\title{
Proteinase-Activated Receptor-2 Mediates Itch: A Novel Pathway for Pruritus in Human Skin
}

\author{
Martin Steinhoff, ${ }^{4 *}$ Ulrich Neisius, ${ }^{1,2 *}$ Akihiko Ikoma, ${ }^{1}$ Manigé Fartasch, ${ }^{2}$ Gisela Heyer, ${ }^{2}$ Per S. Skov, ${ }^{3}$ \\ Thomas A. Luger, ${ }^{4}$ and Martin Schmelz ${ }^{1,5}$ \\ Departments of ${ }^{1}$ Physiology and Experimental Pathophysiology, and ${ }^{2}$ Dermatology, University of Erlangen, 91054 Erlangen, Germany, ${ }^{3}$ The Reference \\ Laboratory, University of Copenhagen, 2100 Copenhagen, Denmark, ${ }^{4}$ Department of Dermatology, University of Münster, 48149 Münster, Germany, and \\ ${ }^{5}$ Department of Anesthesiology and Intensive Care Medicine, University of Heidelberg, 68135 Mannheim, Germany
}

We examined whether neuronal proteinase-activated receptor-2 (PAR-2) may be involved in pruritus of human skin. The endogenous PAR-2 agonist tryptase was increased up to fourfold in atopic dermatitis (AD) patients. PAR-2 was markedly enhanced on primary afferent nerve fibers in skin biopsies of AD patients. Intracutaneous injection of endogenous PAR-2 agonists provoked enhanced and prolonged itch when applied intralesionally. Moreover, itch upon mast cell degranulation was abolished by local antihistamines in controls but prevailed in AD patients. Thus, we identified enhanced PAR-2 signaling as a new link between inflammatory and sensory phenomena in AD patients. PAR-2 therefore represents a promising therapeutic target for the treatment of cutaneous neurogenic inflammation and pruritus.

Key words: protease-activated receptors; neuroimmunology; neurophysiology; sensory nerve; atopy; tryptase

\section{Introduction}

Recent findings on a specific pathway for itch (Schmelz et al., 1997; Andrew and Craig, 2001) have clarified the neurophysiological basis for pruritus. Histamine has been used for decades for experimental itch studies and is responsible for the induction of pruritus in some itchy dermatoses combined with mast cell degranulation like urticaria. However, it has become clear that it is not the main pruritic mediator in the majority of diseases characterized by chronic itch such as atopic dermatitis (AD) (Klein and Clark, 1999). Interestingly, proteinases like papain were identified as histamine-independent itch mediators several decades ago (Rajka, 1969; Hägermark, 1973) but have not received much attention in recent years. The identification of specific proteinase-activated receptors [proteinase-activated receptor-2 (PAR-2)] on afferent nerve fibers (Steinhoff et al., 2000) has initiated various successful studies investigating the role of PAR-2 in the pain pathway (Vergnolle et al., 2001a,b; Fiorucci and Distrutti, 2002). Meanwhile, there is convincing evidence for an involvement of PAR-2 in the activation and sensitization of both somatic (Steinhoff et al., 2000; Kawabata et al., 2001) and visceral afferent nerve fibers (Corvera et al., 1999; Hoogerwerf et al., 2001; Coelho et al., 2002). Apart from its involvement in the pain pathway, recent results from PAR-2 knock-out mice also indicate a

\footnotetext{
Received Nov. 13, 2002; revised April 18, 2003; accepted May 2, 2003.

This work was supported by the Deutsche Forschungsgemeinschaft [Sonderforschungsbereich (SFB) 293 and SFB 353]. We thank the referees for their most valuable comments.

${ }^{*}$ M.S. and U.N. contributed equally to this work.

Correspondence should be addressed to Dr. Martin Schmelz, Department of Anesthesiology and Intensive Care Medicine, Faculty of Clinical Medicine Mannheim, University of Heidelberg, Theodor-Kutzer Ufer 1-3, 68135 Mannheim, Germany. E-mail: martin.schmelz@anaes.ma.uni-heidelberg.de.

Copyright $\odot 2003$ Society for Neuroscience $\quad 0270-6474 / 03 / 236176-05 \$ 15.00 / 0$
}

role of PAR-2 in itchy skin diseases, including atopic dermatitis (Kawagoe et al., 2002).

We therefore investigated the role of PAR-2 signaling in the induction of pruritus in $\mathrm{AD}$ patients. The study included measurement of intradermal concentrations of the endogenous specific PAR-2 agonist mast cell tryptase by dermal microdialysis and assessment of PAR-2 density in skin biopsies by immunohistochemistry. In addition, vascular and neuronal responses to injection of the endogenous ligand (SLIGKV) were assessed in the patients and controls.

\section{Materials and Methods}

Subjects. Thirty-three healthy volunteers ( 17 male, 16 female; mean \pm SD age, $26.5 \pm 0.9$ years) and $38 \mathrm{AD}$ patients ( 17 male, 21 female; mean $\pm \mathrm{SD}$ age, $25.4 \pm 0.5$ years) participated in the study after giving informed consent. The study was approved by the local ethics committees at the University of Erlangen (microdialysis and psychophysics) and University of Münster (histology). AD was diagnosed according to the criteria of Hanifin and Rajka (1980) and Diepgen et al. (1989), using an atopy score consisting of basic and minor features of AD. The score level of AD ranged from 9 to 20 (average score level, 12). Exclusion criteria for $\mathrm{AD}$ patients were the following: systemic steroid therapy during the last 3 months, topical corticosteroid therapy on the volar forearm, or systemic antihistamines $<3$ weeks before the experiments. Healthy volunteers served as a control group; they had no signs of atopy or dermatological diseases and had not received systemic or topical corticosteroids during the last 3 months.

Microdialysis. Subjects were seated comfortably on a reclining chair in a temperature-controlled laboratory $\left(21^{\circ} \mathrm{C} ; 60 \%\right.$ relative humidity). Up to five microdialysis catheters $(0.4 \mathrm{~mm}$ in diameter; cutoff, $3000 \mathrm{kDa}$; DermalDialysis, Erlangen, Germany) were inserted intracutaneously at a length of $1.5 \mathrm{~cm}$ in the nonlesional skin of the volar forearm using a 25 -gauge cannula as described previously (Weidner et al., 2000). No local anesthesia was required. All of the microdialysis catheters were oriented 
transverse to the axis of the volar forearm, and a distance of $4 \mathrm{~cm}$ between each capillary was used. They were perfused with Ringer's solution (Fresenius, Bad Homburg, Germany) by a microdialysis pump (pump 22; Harvard Apparatus, Holliston, MA) at a constant flow rate of $4 \mu \mathrm{l} / \mathrm{min}$ via a Tygon tubing (Novodirect, Kehl, Germany). After a baseline of 60 $\mathrm{min}$, catheters were perfused with different concentrations of codeine phosphate $(0.003-3 \mathrm{mg} / \mathrm{ml})$ or codeine phosphate containing ceterizine (200 $\mu \mathrm{g} / \mathrm{ml}$; Zyrtec; Cassella-Riedel Pharma, Frankfurt, Germany) in a separate session at least 1 week apart. For the combined stimulation of codeine and ceterizine, an $\mathrm{H}_{1}$ blocker was also given during baseline. Dialysate was sampled at $15 \mathrm{~min}$ intervals for a total period of $120 \mathrm{~min}$. Relative recovery for the mediators was $24 \pm 3 \%$ for histamine $\left(10^{-6} \mathrm{M}\right)$ and $22 \pm 5 \%$ for tryptase $(100 \mathrm{pg} / \mathrm{ml})$. Histamine concentration in the dialysate was measured by a fiber-based spectrofluorometric assay as described previously (Petersen et al., 1994). Mast cell tryptase concentration in the dialysate was measured by using specific immunoassays (UniCAP Tryptase; Pharmacia \& Upjohn, Freiburg, Germany) [using the protocol of Schwartz et al. (1990) for isolation of tryptase], according to the manufacturer's instructions.

Tethered ligand injection. In a separate psychophysical experiment, 50 $\mu \mathrm{l}$ of Ringer's solution containing the PAR-2 agonist SLIGKV- $\mathrm{NH}_{2}$ or the reversed peptide VKGILS- $\mathrm{NH}_{2}\left(5 \times 10^{-4}\right.$ to $5 \times 10^{-3} \mathrm{M}$; Bachem, Heidelberg, Germany) was injected into the volar forearm of subjects and patients in random order. They were asked to separately rate the intensity of pain and itch at intervals of $10 \mathrm{sec}$ after the injection on a numerical scale from 0 (no sensation) to 10 (maximum sensation imaginable). In the patients, injections were given in visually unaffected areas of the volar forearm as well as inside their eczema in their cubital fossae. In the subjects, all of the injections were given in their cubital fossae. Injections were spaced by at least $3 \mathrm{~cm}$.

Histology. Double immunofluorescence staining was performed with modifications as described previously (Steinhoff et al., 2000). Briefly, skin biopsies were taken from postoperative material (healthy controls; $n=6$ ) or lesional and nonlesional skin of patients suffering from atopic dermatitis $(n=8)$. Patients did not receive topical antiinflammatory agents at the sites of inflammation, systemic medications, or UV irradiation within 2 weeks before biopsies were obtained. Tissues were fixed in Bouin's fixative for $12 \mathrm{hr}$, embedded in optimal cutting temperature compound (Miles, Elkhart, IN), and stored at $-80^{\circ} \mathrm{C}$. Before use, specimen were sectioned, postfixed with Bouin's fixative for $20 \mathrm{~min}$, and washed in PBS, pH 7.4, for 45 min. Sections were incubated with antibodies against PAR-2 (PAR-2 B5; 1:500; kindly provided by Morley Hollenberg (Johns Hopkins University, Baltimore, MD); PAR-2 C-17; 1:100, Santa Cruz Biotechnology, Santa Cruz, CA) overnight at $4^{\circ} \mathrm{C}$ as described previously (Steinhoff et al., 2000), followed by incubation with mouse monoclonal antibody against mast cell tryptase (1:2000) for $1 \mathrm{hr}$ at room temperature. After thorough washing in PBS three times for 10 min each, slides were incubated in a PBS buffer containing 5\% normal goat serum and $1 \%$ bovine serum albumin with a mixture of secondary antibodies [goat anti-rabbit Ig (1:200; B5; Dako, Hamburg, Germany) or sheep anti-goat Ig (1:200; C-17; Santa Cruz Biotechnology), respectively, and donkey anti-mouse IgG (1:100; Amersham Biosciences, Braunschweig, Germany)]. After washing in a dark chamber, slides were mounted in Vectashield (Vector Laboratories, Burlingame, CA) and examined using a Leica (Nussloch, Germany) DMR microscope. In controls, primary polyclonal antibodies were preincubated for $24-48 \mathrm{hr}$ with corresponding peptides (10-100 $\mu \mathrm{M}$; B5, GPNSKGRSLIGRLDTP-YGGC; C-17, sc8205 P; Santa Cruz Biotechnology) used for immunization, or matched monoclonal Ig control antibodies were used to elucidate background staining. Semiquantitative analysis was performed on coded sections by two independent observers as described previously (Steinhoff et al., 2000). The number of positive nerves was analyzed by counting identical staining of three subsequent slides from one block. Four blocks from four persons were counted per group. Similar regions (forearm) with comparable total numbers of nerve fibers, as determined by staining with protein gene product (PGP) 9.5 (mouse monoclonal antibody; 1:100 dilution; Accurate Chemicals, Westbury, NY), were used. Mouse tachykinin antibody was from Chemicon (Temecula, CA) (1:2000 dilution).

Statistics. For statistical evaluation, an ANOVA for repeated measures

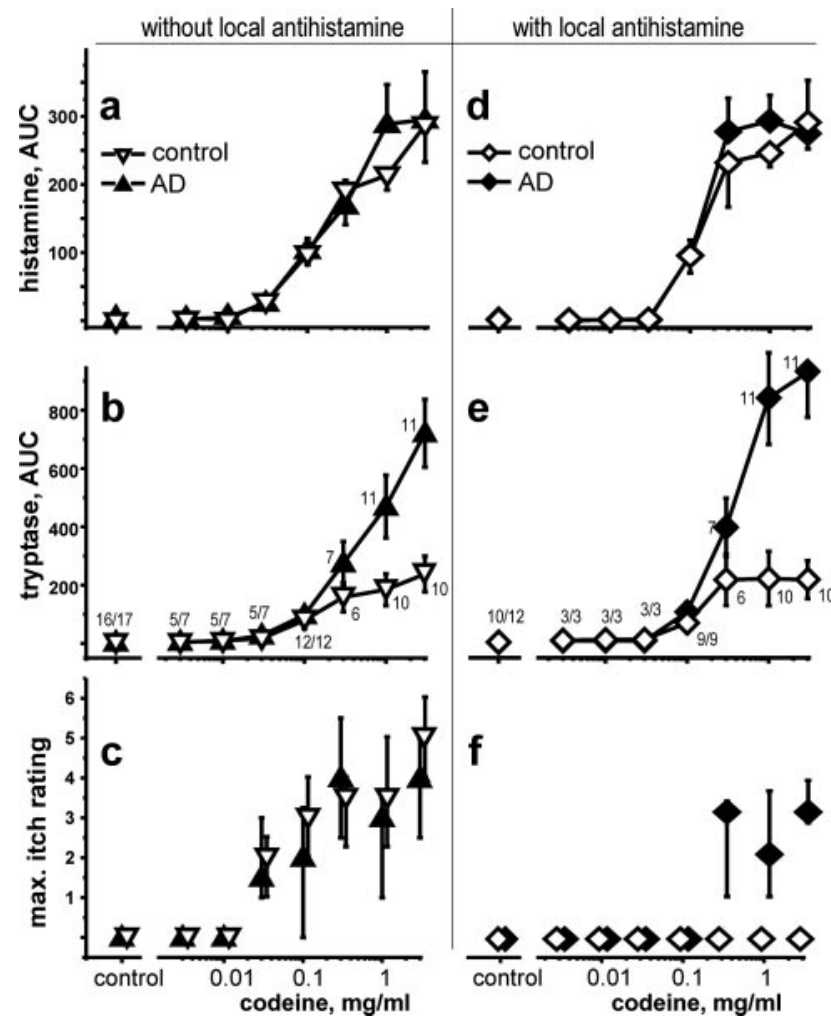

Figure 1. Dose-response relationship of codeine-induced release of histamine $(a)$ and tryptase (b) (mean \pm SD) and of intensity of itch (scale from 0 to 10$)(c)$ (median, quartiles) in controls (open triangles) and patients with $\mathrm{AD}$ (filled triangles). Codeine phosphate was applied via intradermal microdialysis catheters for $30 \mathrm{~min}$ after a baseline perfusion of $60 \mathrm{~min}$, and mediator release was measured in the perfusate at 15 min intervals. In a second session, codeine applications were repeated with a histamine receptor antagonist (ceterizine; $100 \mu \mathrm{g} / \mathrm{ml}$ ) applied during the entire protocol ( $d-f$, open and filled diamonds). The numbers of subjects or patients are indicated in $b$ and . AUC, Area under the curve; max., maximum.

was used, followed by Scheffé's post hoc tests to locate significant differences. Values of $p<5 \%$ were considered significant. Values are given as mean \pm SEM or median and quartiles, as appropriate.

\section{Results}

\section{Codeine-induced mediator release}

In $\mathrm{AD}$ patients, codeine-induced tryptase release exceeded by far the control values, as can be judged in the dose-response relationship (Fig. 1). Stimulated tryptase release in AD patients was more pronounced at codeine concentrations of $\geq 0.3 \mathrm{mg}$ and reached approximately fourfold higher values after maximum stimulation with codeine.

Similarly, histamine concentration in AD was higher compared with control after insertion of the dialysis catheter (mean \pm SEM, $22.4 \pm 4.4$ vs $9.2 \pm 0.9 \mathrm{pg} / \mathrm{ml} ; n=53$ vs $46 ; p<0.01, t$ test $)$ (data not shown). However, codeine-induced histamine release did not differ significantly between the groups (Fig. 1). Mean peak levels were $287 \pm 55 \mathrm{pg} / \mathrm{ml}$ (mean \pm SEM; $n=12)$ in controls and $292 \pm 39 \mathrm{pg} / \mathrm{ml}$ (mean \pm SEM; $n=12$ ) in AD.

The codeine-induced mast cell degranulation was accompanied by a dose-dependent pruritus, which did not differ significantly between the groups under control conditions. Coadministration of ceterizine in a separate session abolished codeineinduced pruritus in controls only. In contrast, $\mathrm{AD}$ patients still experienced moderate to medium pruritus at codeine concentrations of $\geq 0.3 \mathrm{mg} / \mathrm{ml}$ (Fig. 1 ). 


\section{Immunohistochemistry}

In lesional skin of patients with atopic dermatitis, staining for PAR-2 (PAR-2 B5; red) can be observed in keratinocytes, blood vessels, certain inflammatory cells, and nerve-fiber-like structures (Fig. 2a). Nerve fibers can hardly be seen at lower magnifications because of the staining of several dermal cells. Mast cells (green) are found in dermal compartments close to blood vessels (Fig. 2a) (100×). Omission of antibodies against PAR-2 demonstrates only staining of mast cells by tryptase (Fig. $2 b)(100 \times)$. Higher magnification reveals staining of small nerve fibers (arrow) in the dermis associated with blood vessels (red) and mast cells (green) (Fig. 2c) $(400 \times)$. In lesional skin of patients with $\mathrm{AD}$, increased staining for PAR-2 was observed in nerve fibers (arrows) closely associated with mast cells (green) (Fig. 2d) $(630 \times)$ at higher magnification. Moderate staining for PAR-2 (arrows) was also observed in nerve fibers of nonlesional skin from patients with $\mathrm{AD}$, whereas weak to negative staining was observed in normal human skin (Fig. 2e). Preabsorption control staining (PAR-2 B5 peptide) did not result in any PAR-2-like immunoreactivity in either human skin tissue (Fig. $2 f$ ). Identical results were obtained for both of the antisera described in Materials and Methods using the appropriate competing peptide.

Semiquantitative analysis of immunostaining was also performed to elucidate potential differences in normal and disease skin. Therefore, we stained various tissues for PAR-2 and PGP 9.5 or substance P (SP), respectively. Staining positivity was counted in triplicate from at least six tissues per group by using semiquantitative analysis. Data revealed differences in PAR2-like immunoreactivity in cutaneous nerve fibers. Of all nerves detected by staining for PGP 9.5, $63 \pm$ $8 \%(n=8$; triplicate) exhibited PAR-2-like immunoreactivity in lesional skin. In nonlesional skin, $38 \pm 8 \%(n=6$; triplicate $)$ of all nerves stained for PGP 9.5 contained PAR-2-like immunoreactivity. We detected PAR-2-like immunoreactivity in $13 \pm 10 \%$ ( $n=6$; triplicate) of all nerve fibers stained for PGP 9.5 in healthy volunteers. Thus, dermal nerves of atopic dermatitis show enhanced PAR-2-like immunoreactivity compared with those of normal skin. This difference was significantly increased in dermal sensory nerves stained for SP. Whereas $75 \pm 8 \%(n=4$; triplicate) of all SP-positive nerves stained for PAR-2 in lesional skin, $46 \pm 4 \%(n=6$; triplicate $)$ of all nerves staining for SP also contained PAR-2-like immunoreactivity in nonlesional skin. In healthy skin, $25 \pm 12 \%$ ( $n=4$; triplicate $)$ of all neurons stained for SP also contained PAR-2. Together, PAR-2-like immunoreactivity was predominantly detected in sensory and, to a lesser extent, in nonsensory nerves of lesional, nonlesional, and healthy human skin. PAR-2-positive fibers are increased in lesional skin of $\mathrm{AD}$ patients. However, PAR-2 immunoreactivity is enhanced in nonlesional skin of $\mathrm{AD}$ patients compared with normal human skin. This may explain why patients with $\mathrm{AD}$ show increased susceptibility to itch sensations on clinically healthy skin.

\section{PAR-2-induced sensations}

Intracutaneous injection of the endogenous PAR-2 agonist SLIGKV dose-dependently provoked pain upon injection, and this pain was followed by an itch sensation lasting for $\sim 2-5$ min. Cumulative itch ratings were higher for injections in nonlesional skin of $\mathrm{AD}$ patients for 1 and $5 \mathrm{~mm}$ tethered ligand, but this difference did not reach statistical significance $(p=0.15$; ANOVA; planned comparison). However, when applied inside the eczema, SLIGKV provoked enhanced itch in the patients compared with that of control ( $p<0.05$; ANOVA; Scheffé post hoc). At higher concentrations, the reversed peptide VKGILS also provoked an itch response (Fig. 3, right). However, at a concentration of $0.5 \mathrm{~mm}$, only the active agonist SLIGKV induced an itch response, when applied in the eczema. 


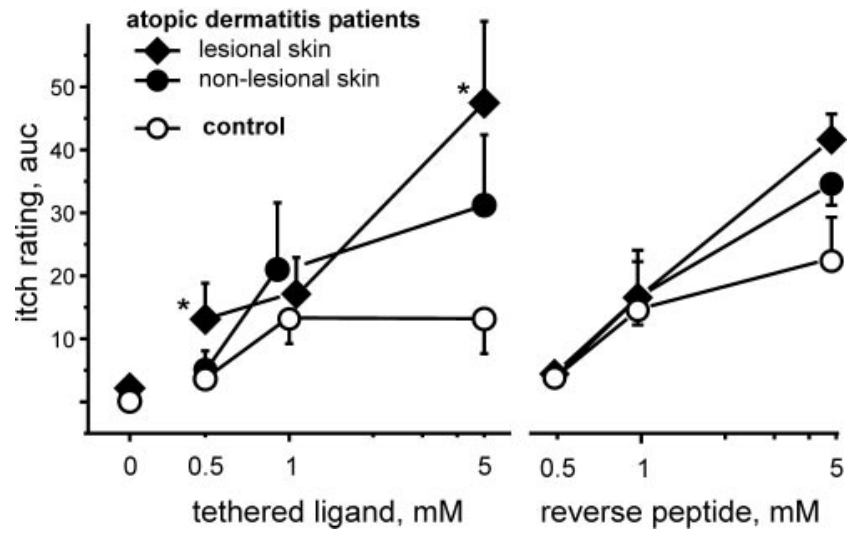

Figure 3. Dose-response curves for itch induction by intracutaneous injection of a PAR-2 agonist [tethered ligand; $50 \mu \mathrm{l} ; 13$ controls (open circles) and 14 AD patients (filled diamonds, lesional skin; filled circles, nonlesional skin)] and the reverse peptide (VKGILS-NH ${ }_{2} ; 6$ controls and $4 A D$ patients) are shown. Intensity of itch sensation after the injection was assessed on a scale from 0 to 10 at 10 sec intervals for 5 min. auc, Area under the curve; mean \pm SEM.

\section{Discussion}

After the identification of PAR-2 on afferent nerve fibers (Steinhoff et al., 2000), the role of proteinase-activated receptors in the pain pathway has become of major interest (Vergnolle et al., 2001a,b; Fiorucci and Distrutti, 2002). Meanwhile, there is convincing evidence for an involvement of PAR-2 for activation and sensitization of both somatic (Steinhoff et al., 2000; Kawabata et al., 2001) and visceral afferent nerve fibers (Corvera et al., 1999; Hoogerwerf et al., 2001; Coelho et al., 2002).

Interestingly, proteinases like papain were identified several decades ago to be histamine-independent itch mediators (Rajka, 1969; Hägermark, 1973). However, these observations have not received much attention in the recent past. The recent finding that, in $\mathrm{AD}$ patients, itch upon degranulation of mast cells could not be suppressed by antihistamines (Rukwied et al., 2000) suggested that mast cell mediators other than histamine could act as important itch mediators in $\mathrm{AD}$. In line with these observations, our results indicate increased signaling via PAR-2 in AD patients, which is characterized by the release of a higher concentration of the putative endogenous PAR-2 agonist mast cell tryptase, a higher density of PAR-2 on epidermal nerves, keratinocytes, and endothelia, and finally enhanced responsiveness of the patients toward exogenously applied PAR-2 agonist.

Higher tryptase concentrations could be attributed simply to the higher number of mast cells found in AD patients (Damsgaard et al., 1997). Interestingly, only codeine-induced tryptase, but not histamine release, was found to be increased in $\mathrm{AD}$. Thus, a higher level of tryptase in the mast cells or a higher percentage of tryptase-positive mast cells (Jarvikallio et al., 1997) has to be assumed. Increased tryptase levels alone cannot account entirely for the histamine-independent itch upon mast cell degranulation. The highest codeine concentration provoked considerable tryptase release in normals also, but no concomitant itch sensation was observed when $\mathrm{H}_{1}$ blockers were coapplied. Therefore, increased expression of PAR-2 on dermal nerves in $\mathrm{AD}$ patients represents a critical finding. Moreover, the close proximity of nerves and mast cells may indicate functional interdependence (Bauer and Razin, 2000). Increased density of PAR-2 on lesional and nonlesional skin nociceptors may also underlie the higher sensitivity of $\mathrm{AD}$ patients to injection of the PAR-2-activating tethered ligand. At higher concentrations, even the nonactive reverse peptide provoked itch in patients and controls, probably because of mast cell activation. It is important to note, however, that the role of human tryptase as an endogenous activator of PAR-2 is not entirely clear, because tryptase cannot activate the fully glycosylated receptor (Compton et al., 2002a,b). Thus, it is possible that either a mast cell proteinase other than tryptase may be responsible for PAR-2 activation, or the glycosylation state of PAR-2 in sensory nerves may be modulated to make the receptor susceptible to tryptase activation.

Recent results suggest that the itch sensation is processed by a specific neuronal pathway (Schmelz et al., 1997; Andrew and Craig, 2001). Enhanced itch upon application of PAR-2 agonists in the patients could therefore indicate a selective increase of PAR-2 on peripheral itch-specific neurons. However, the subtypes of unmyelinated afferent nerve fibers subserving itch or pain processing can be differentiated functionally only according to their histamine response. There is no marker available to identify itch-specific neurons, and thus, the relative increase of PAR-2 receptors cannot be compared between fibers of the pain- and itch-processing systems.

Apart from neuronal cells, increased PAR-2 signaling will also affect keratinocytes, endothelia, epithelia, smooth muscle cells, and inflammatory cells, all of which have been implicated in the pathophysiology of various chronic inflammatory diseases (Knight et al., 2001; Vergnolle et al., 2001a,b; Miotto et al., 2002), in particular atopic dermatitis. Our study confirms that PAR-2 is expressed on keratinocytes (Santulli et al., 1995) and endothelia. Activation of PAR-2 on keratinocytes (Kanke et al., 2001) and on endothelia (Shpacovitch et al., 2002) stimulates nuclear factor $\kappa \mathrm{B}$ signaling, which has been speculated to be linked to atopic dermatitis (Huber et al., 2002). Moreover, PAR-2 activation increases the release of IL-6 and granulocyte-macrophage colonystimulating factor (Wakita et al., 1997), which has been found to be elevated in keratinocytes of AD patients (Pastore et al., 2000). The importance of PAR-2 signaling for the induction of dermatitis has recently been shown by a markedly decreased contact dermatitis in PAR-2 knock-out mice (Kawagoe et al., 2002). Because PAR-2 is expressed by various inflammatory cells including mast cells (D'Andrea et al., 2000) and T cells (Bar-Shavit et al., 2002), one may speculate that PAR-2 is critically involved in both neurogenic and non-neurogenic inflammation of human skin. It should also be noted that there is a complex cross-talk among inflammatory cells with a major role in the interaction between mast cells and T cells in AD (Zhang et al., 1995; Mekori and Metcalfe, 1999; Gibbs et al., 2001; Shelburne and Ryan, 2001; Alenius et al., 2002).

In summary, proteinases appear to play an important role as itch mediators in human skin very likely by activating PAR-2. The existence of a histamine-independent, proteinase-dependent, and PAR-2-mediated itch pathway provides a new link that may lead to beneficial therapies for pruritus and cutaneous inflammation.

\section{References}

Alenius H, Laouini D, Woodward A, Mizoguchi E, Bhan AK, Castigli E, Oettgen HC, Geha RS (2002) Mast cells regulate IFN- $\gamma$ expression in the skin and circulating IgE levels in allergen-induced skin inflammation. J Allergy Clin Immunol 109:106-113.

Andrew D, Craig AD (2001) Spinothalamic lamina 1 neurons selectively sensitive to histamine: a central neural pathway for itch. Nat Neurosci 4:72-77.

Bar-Shavit R, Maoz M, Yongjun Y, Groysman M, Dekel I, Katzav S (2002) Signalling pathways induced by protease-activated receptors and integrins in T cells. Immunology 105:35-46.

Bauer O, Razin E (2000) Mast cell-nerve interactions. News Physiol Sci. 15:213-218.

Coelho AM, Vergnolle N, Guiard B, Fioramonti J, Bueno L (2002) Protein- 
ases and proteinase-activated receptor 2: a possible role to promote visceral hyperalgesia in rats. Gastroenterology 122:1035-1047.

Compton SJ, McGuire JJ, Saifeddine M, Hollenberg MD (2002a) Restricted ability of human mast cell tryptase to activate proteinase-activated receptor-2 in rat aorta. Can J Physiol Pharmacol 80:987-992.

Compton SJ, Sandhu S, Wijesuriya SJ, Hollenberg MD (2002b) Glycosylation of human proteinase-activated receptor-2 (hPAR2): role in cell surface expression and signalling. Biochem J 368:495-505.

Corvera CU, Dery O, McConalogue K, Gamp P, Thoma M, Al Ani B, Caughey GH, Hollenberg MD, Bunnett NW (1999) Thrombin and mast cell tryptase regulate guinea-pig myenteric neurons through proteinaseactivated receptors-1 and -2. J Physiol (Lond) 517:741-756.

Damsgaard TE, Olesen AB, Sorensen FB, Thestrup-Pedersen K, Schiotz PO (1997) Mast cells and atopic dermatitis. Stereological quantification of mast cells in atopic dermatitis and normal human skin. Arch Dermatol Res 289:256-260.

D'Andrea MR, Rogahn CJ, Andrade-Gordon P (2000) Localization of protease-activated receptors- 1 and -2 in human mast cells: indications for an amplified mast cell degranulation cascade. Biotech Histochem 75:85-90.

Diepgen TL, Fartasch M, Hornstein OP (1989) Evaluation and relevance of atopic basic and minor features in patients with atopic dermatitis and in the general population. Acta Derm Venereol Suppl (Stockh) 144:50-54.

Fiorucci S, Distrutti E (2002) Role of PAR2 in pain and inflammation. Trends Pharmacol Sci 23:153-155.

Gibbs BF, Wierecky J, Welker P, Henz BM, Wolff HH, Grabbe J (2001) Human skin mast cells rapidly release preformed and newly generated TNF- $\alpha$ and IL- 8 following stimulation with anti-IgE and other secretagogues. Exp Dermatol 10:312-320.

Hägermark O (1973) Influence of antihistamines, sedatives, and aspirin on experimental itch. Acta Derm Venereol 53:363-368.

Hanifin JM, Rajka G (1980) Diagnostic features of atopic dermatitis. Acta Derm Venereol Suppl (Stockh) 92:44-77.

Hoogerwerf WA, Zou L, Shenoy M, Sun D, Micci MA, Lee-Hellmich H, Xiao SY, Winston JH, Pasricha PJ (2001) The proteinase-activated receptor 2 is involved in nociception. J Neurosci 21:9036-9042.

Huber MA, Denk A, Peter RU, Weber L, Kraut N, Wirth T (2002) The IKK $-2 / \mathrm{I} \kappa \mathrm{B} \alpha / \mathrm{NF}-\kappa \mathrm{B}$ pathway plays a key role in the regulation of CCR3 and eotaxin-1 in fibroblasts. A critical link to dermatitis in $\mathrm{I} \kappa \mathrm{B} \alpha$-deficient mice. J Biol Chem 277:1268-1275.

Jarvikallio A, Naukkarinen A, Harvima IT, Aalto ML, Horsmanheimo M (1997) Quantitative analysis of tryptase- and chymase-containing mast cells in atopic dermatitis and nummular eczema. Br J Dermatol 136:871-877.

Kanke T, Macfarlane SR, Seatter MJ, Davenport E, Paul A, McKenzie RC, Plevin R (2001) Proteinase-activated receptor-2-mediated activation of stress-activated protein kinases and inhibitory $\kappa \mathrm{B}$ kinases in NCTC 2544 keratinocytes. J Biol Chem 276:31657-31666.

Kawabata A, Kawao N, Kuroda R, Tanaka A, Itoh H, Nishikawa H (2001) Peripheral PAR-2 triggers thermal hyperalgesia and nociceptive responses in rats. NeuroReport 12:715-719.

Kawagoe J, Takizawa T, Matsumoto J, Tamiya M, Meek SE, Smith AJ, Hunter GD, Plevin R, Saito N, Kanke T, Fujii M, Wada Y (2002) Effect of protease-activated receptor-2 deficiency on allergic dermatitis in the mouse ear. Jpn J Pharmacol 88:77-84.

Klein PA, Clark RA (1999) An evidence-based review of the efficacy of antihistamines in relieving pruritus in atopic dermatitis. Arch Dermatol 135:1522-1525.

Knight DA, Lim S, Scaffidi AK, Roche N, Chung KF, Stewart GA, Thompson PJ (2001) Protease-activated receptors in human airways: upregulation of PAR-2 in respiratory epithelium from patients with asthma. J Allergy Clin Immunol 108:797-803.
Mekori YA, Metcalfe DD (1999) Mast cell-T cell interactions. J Allergy Clin Immunol 104:517-523.

Miotto D, Hollenberg MD, Bunnett NW, Papi A, Braccioni F, Boschetto P, Rea F, Zuin A, Geppetti P, Saetta M, Maestrelli P, Fabbri LM, Mapp CE (2002) Expression of protease activated receptor-2 (PAR-2) in central airways of smokers and non-smokers. Thorax 57:146-151.

Pastore S, Giustizieri ML, Mascia F, Giannetti A, Kaushansky K, Girolomoni G (2000) Dysregulated activation of activator protein 1 in keratinocytes of atopic dermatitis patients with enhanced expression of granulocyte/ macrophage-colony stimulating factor. J Invest Dermatol 115:1134-1143.

Petersen LJ, Poulsen LK, Sondergaard J, Skov PS (1994) The use of cutaneous microdialysis to measure substance P-induced histamine release in intact human skin in vivo. J Allergy Clin Immunol 94:773-783.

Rajka G (1969) Latency and duration of pruritus elicited by trypsin in aged patients with itching eczema and psoriasis. Acta Derm Venereol 49:401-403.

Rukwied R, Lischetzki G, McGlone F, Heyer G, Schmelz M (2000) Mast cell mediators other than histamine induce pruritus in atopic dermatitis patients: a dermal microdialysis study. Br J Dermatol 142:1114-1120.

Santulli RJ, Derian CK, Darrow AL, Tomko KA, Eckardt AJ, Seiberg M, Scarborough RM, Andrade-Gordon P (1995) Evidence for the presence of a protease-activated receptor distinct from the thrombin receptor in human keratinocytes. Proc Natl Acad Sci USA 92:9151-9155.

Schmelz M, Schmidt R, Bickel A, Handwerker HO, Torebjörk HE (1997) Specific C-receptors for itch in human skin. J Neurosci 17:8003-8008.

Schwartz LB, Bradford TR, Lee DC, Chlebowski JF (1990) Immunologic and physicochemical evidence for conformational changes occurring on conversion of human mast cell tryptase from active tetramer to inactive monomer. Production of monoclonal antibodies recognizing active tryptase. J Immunol 144:2304-2311.

Shelburne CP, Ryan JJ (2001) The role of Th2 cytokines in mast cell homeostasis. Immunol Rev 179:82-93.

Shpacovitch VM, Brzoska T, Buddenkotte J, Stroh C, Sommerhoff CP, Ansel JC, Schulze-Osthoff K, Bunnett NW, Luger TA, Steinhoff M (2002) Agonists of proteinase-activated receptor 2 induce cytokine release and activation of nuclear transcription factor $\kappa \mathrm{B}$ in human dermal microvascular endothelial cells. J Invest Dermatol 118:380-385.

Steinhoff M, Vergnolle N, Young SH, Tognetto M, Amadesi S, Ennes HS, Trevisani M, Hollenberg MD, Wallace JL, Caughey GH, Mitchell SE, Williams LM, Geppetti P, Mayer EA, Bunnett NW (2000) Agonists of proteinase-activated receptor 2 induce inflammation by a neurogenic mechanism. Nat Med 6:151-158.

Vergnolle N, Wallace JL, Bunnett NW, Hollenberg MD (2001a) Proteaseactivated receptors in inflammation, neuronal signaling and pain. Trends Pharmacol Sci 22:146-152.

Vergnolle N, Bunnett NW, Sharkey KA, Brussee V, Compton SJ, Grady EF, Cirino G, Gerard N, Basbaum AI, Andrade-Gordon P, Hollenberg MD, Wallace JL (2001b) Proteinase-activated receptor-2 and hyperalgesia: a novel pain pathway. Nat Med 7:821-826.

Wakita H, Furukawa F, Takigawa M (1997) Thrombin and trypsin induce granulocyte-macrophage colony-stimulating factor and interleukin-6 gene expression in cultured normal human keratinocytes. Proc Assoc Am Physicians 109:190-207.

Weidner C, Klede M, Rukwied R, Lischetzki G, Neisius U, Skov PS, Petersen LJ, Schmelz M (2000) Acute effects of substance P and calcitonin generelated peptide in human skin-a microdialysis study. J Invest Dermatol 115:1015-1020.

Zhang Y, Ramos BF, Jakschik B, Baganoff MP, Deppeler CL, Meyer DM, Widomski DL, Fretland DJ, Bolanowski MA (1995) Interleukin 8 and mast cell-generated tumor necrosis factor- $\alpha$ in neutrophil recruitment. Inflammation 19:119-132. 